\title{
Aestheticization of Daily Life and Post-Modernism Design
}

\author{
Xiaofan GONG \\ School of Design \& Art, Beijing Institute of Graphic Communication, China
}

\begin{abstract}
Aestheticization of daily life is one of the key features of post-modernism culture. In contemporary design activities, post-modernism design connects life and art, featuring both functionality and aesthetics, instrumentality and social cultural values, hence an important example of post-modernism cultural and aestheticization of daily life. The aesthetic characteristics of post-modernism design are mainly reflected in three aspects, namely decorative style, eclecticism style and multiple symbolic connotations. Postmodernism design reflects significant changes of design in the contemporary context, and its objective has evolved from pure functional design to a socio-cultural phenomenon with rich connotations and an exploration with multiple purposes.
\end{abstract}

KEYWORD: Aestheticization of daily life; Post-modernism design, postmodernism culture

In contemporary design activities, post-modernism design has become a typical example of aestheticization of contemporary daily life as well as an important sample of post-modernism culture as it connects life and art as an embodiment of functionality and aesthetics, instrumentality and socio-cultural values. Post-modernism design reflects significant changes of design in the contemporary context, and its objective has evolved from pure functional design to a socio-cultural phenomenon with rich connotations and an exploration with multiple purposes. In a sense, designed product has become a cultural symbol and quasi-artwork, which is the very reason that contemporary design, including post-modernism design, has become an important cultural pattern with which contemporary social life is interpreted

\section{THE PARTICIPATION PROCESS OF CONTEMPORARY DESIGN IN AESTHETICIZATION OF DAILY LIFE}

As a significant feature of post-modernism culture, aestheticization of daily life has drawn much attention and initiated extensive discussions among researchers. Mike Featherstone summarized the aestheticization of daily life in three aspects[1]: first, bringing art into life, which appears as anti-art to challenge the existing concept of art and deconstruct the sacred aureole of art, portraying the triviality or even vulgarity in daily life as themes of art representation, or directly identifying ready-made daily objects as artworks. The former is exemplified by the paintings of canned soup by Andy Warhol while the latter, by Marcel Duchamp who displayed the "ready-made" art consisting of urinals and bicycle wheels. Second, the artistic representation of life, i.e. the artistic and aesthetic representation of daily life and the transfer of art representation into the scenarios, objects and behaviors in daily life, where various objects closely related to basic necessities of life offering specific aesthetic pleasures while delivering value in use. An example is the aestheticism in the $19^{\text {th }}$ century represented by Oscar Wilde. Third, ubiquit ous symbols and images in daily life of the contemporary society. As pointed out by Jean Baudrillard, in the contemporary consumer society, various implications are attached or transplanted to commodities besides their functions, making it a material medium which expresses implications, i.e. a material medium of symbols. Further observation will show that the various objects aesthetically manifested and related to basic necessities of life as described in the second item and the symbolic commodity in the third item, with very few exceptions, are designed products or related to design. And artificial products, as the materialization of design activities, have become a typical pattern indispensible to the phenomenon of artistic life and aestheticization of daily life. 
As pointed out by Featherstone, the aesthetic demonstration of daily life is not only a contemporary phenomenon. As early as in the 1950s, the first large-scale department store "Bon Marche" in Paris placed pans and water pots against a background of an island decorated with seashells, coral beads and palm trees in its window display, illustrating for the public the aesthetic effect of daily objects. The same situation was noted in Britain in the same époque. In the mid- $19^{\text {th }}$ century, William Morris, who wished to become a painter, invited his friends to join him in designing his Red House as well as interior decorations including wallpaper, carpet, furniture, tableware and luminaires for his wedding. These artistic daily objects with a consistent design style defined the style of the Arts \& Crafts Movement later on in Britain.

Today, various ingeniously designed objects and scenarios featuring diversified styles have already become part of the daily life that we are accustomed to, as people are almost inundated in these artificially beautified environments and products. The objects that we feel and interpret as embodiment of aestheticization of daily life are, to a large extent, products of contemporary design, by which the aesthetic objectives and resources provided in daily life have dwarfed contemporary art. Therefore, some argue that "industrial design is the art of the $20^{\text {th }}$ century"; while Baudrillard believes that contemporary design belongs to industrial aestheticism. It is design that bestows a certain aesthetic image on daily objects that surround us, while delivering its special aesthetic pleasures to the contemporary generation.

Truly, practicality, cognition and aestheticism are the general functions of design; yet different designs vary in concepts and characteristics, and not all designed products may be viewed as typical examples of aestheticization of daily life. For a considerable period of time, the focus of design, especially for objects of daily life, was practical functionality. Post-modernism design, however, as a specific style in contemporary design activities, connects life and art and pursues the expression of socio-cultural connotation and aesthetic effects of design, hence becoming an important example of aestheticization of contemporary daily life and postmodernism culture.

Having first emerged in the United States and later casting its influence on Europe and Japan among other countries and regions, post-modernism design is a school of design with extensive influential power on a global scale from the 1960s to the 1990s. Like many styles and schools of modern design, post-modernism design first emerged in architecture, followed by its manifestation in industrial design, objects of daily life and graphic design. Viewed from the relationship between design and social culture, the socio-cultural soil for the emergence of post-modernism design can be traced back to the western world in the 1960s with rapid economic growth, entrance into a consumer society featuring material abundance as well as various socio-cultural resistance movements in the society. From an inner perspective of design, however, postmodernism design is a backwash of the modernism design style featuring rigorous rationalism and functionality as priority, and simplistic, unadorned style. Post-modernism design, on the contrary, is against the uniformity of form and advocates diversity and decorativeness of design form, caring for humanity and emotional expression in design while focusing on the historical and cultural connotation of design. Post-modernism design has therefore constructed its aesthetic image of sensibility, individualistic expression, rich diversity and vividness. Aesthetical features of postmodernism design are mainly reflected in its decorative style, eclectic characteristic and symbolic connotation, etc.

\section{DECORATIVE STYLE OF POST- MODERNISM DESIGN}

Post-modernism design language features sensitivity and decorative beauty, which is in strong contrast with the rationality and anti-decorative style of modernism design. The different attitudes towards decoration between post-modernism and modernism are attributed both to the difference in design concept and aesthetic taste and to the socio-cultural contexts where they are situated. In the beginning of the $20^{\text {th }}$ century, the design field needed a product pattern style best adapted to mechanized industrial production. The concept of functionalism in design refers to the idea that the shape of the product depends on its functions, that the product shall feature its practical functions and that a product which fully accomplishes its functions is beautiful. Modernism design tends to fill its language with geometrical patterns which are abstract and brief. From the beginning of the $20^{\text {th }}$ century to the mid$20^{\text {th }}$ century, low cost and mass production constituted the basic requirements for products for western countries in the context of production society; consequently modernism products centering upon functionalism and featuring a pure and simplistic style which was unadorned, hence suitable for standardized and systematic industrial mass production, became the most representative and influential product type in the first half of the $20^{\text {th }}$ century.

Modernism design centers itself upon functionality. Such functionalism is most influentially and precisely expressed by American architect Louis Sullivan as "form follows function". Modernism design openly condemns decoration, 
viewing decoration as a sin. Viennese architect Adolf Loos even made the statement that "decoration is a sin", believing that decoration was a waste of materials and funds. The pursuit for unadorned simplicity and the condemnation of decoration and extravagance are the consensus of modernism designers.

Post-modernism emerged out of a social environment distinctively different from modernism design. Following the end of World War II, western countries were on the track of gradual economic recovery and fast development. By the 1960s, these countries successively evolved from a production society into a consumer society with rapidly increasing diversity and quantity of social commodity, scarcity replaced by abundance of products and consumption capacity of various social classes. Jean Baudrillard pointed out in his Consumer Society that the fundamental dilemma of the society, rather than the contradiction between "acquisition of maximum profit" and "rationalization of production" (on the level of entrepreneur), was the contradiction between potentially unlimited productivity (on the level of technology structure) and the necessity of product sales"[2]. Therefore, constant launching of new products became a rigid requirement for continuous production, and building functionally identical or similar products into new products through changes in design evolved into a common practice, where decorative processing of products became a necessary means to add to the connotation of design. It can be therefore stated that the decorative style of post-modernism design is a representation for material wealth and economic prosperity.

Post-modernism design, on the other hand, is richly decorative in style, endowing a decorative and sensitive image on the product by adding a certain concrete image or by combining concreteness with abstractness, such as adding a Mickey Mouse or a bird. Strongly emphasizing on decorativeness, postmodernism design identifies decoration both as a means to achieve stylization and aesthetic effect and as part of the objective of design. Post-modernism design achieves certain decorative effects through various means, such as emulation of traditional classical forms, or employment of concrete, semiotic or symbolic, or other forms of elements. In the use of colors, post-modernism design differs itself from modernism design which mainly uses neutral colors such as black, white and grey in that it audaciously employs bright and rich colors to create strong sensory effects. Rather than following the convention of flat rooftop in modernism architecture, American designer Michael Graves in his case of Walt Disney World Swan built a softly arching top and respectively decorated the tops of the main wing and the side wings with two giantsized swans and two sea shells standing like flowers in blossom; he went on to use massive bright orange on the façade of the building, highlighting the entire structure with distinctive art deco and visual effects. Art deco has endowed post-modernism design products with some trace of artworks.

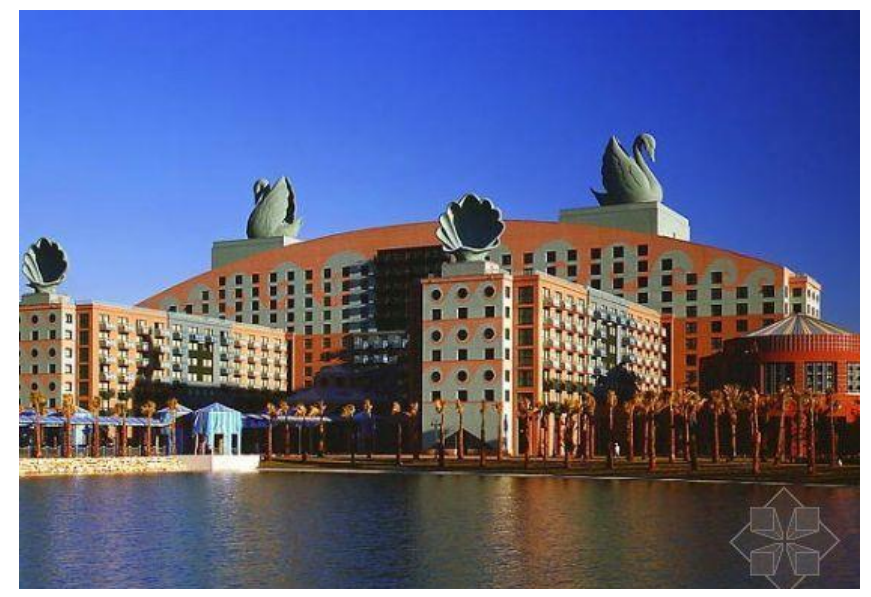

Figur 1. Walt Disney World Swan, Michael Graves, 1990

\section{ECLECTIC STYLE IN POST-MODERNISM DESIGN}

Post-modernism design language features an eclectic style. While modernism design emphasizes the integrality and consistence of style with its purity and exclusiveness of language; post-modernism design tolerates and recognizes the variation and contradiction in design languages, combining style elements of different eras and types and demonstrating a kind of "dynamism in disorder". In 1966, Robert Venturi, a maestro post-modernism designer, published Complexity and Contradiction in Architecture, a book viewed as a manifesto of postmodernism design, in which he advocated a complex and eclectic aesthetic style with the statement of "less is boring", refuting the motto of "less is more" in modernism design. "I am fond of the complexity and contradiction in architecture" said Venturi, proposing to replace the "visible uniformity" of modernism by "dynamism in disorder", arguing for ambiguity rather than clarity [3].

Tolerating the co-existence of various styles, eclecticism in post-modernism design demonstrates itself in the richness and diversity of styles which is reflected both in the patchwork and combination of elements of various sources and styles and in the manifestation of their respective individualistic dispositions by different products in post-modernism design. Piazzad ' Italia, New Orleans designed by American designer Charles Moore constitutes of various historical episodes with Hellenic and Roman columns and arch gates integrated with modern stainless steel, bright colors and neon lights, producing a hybrid, complex style featuring both classicalism and modernity, tradition and avantgarde. 


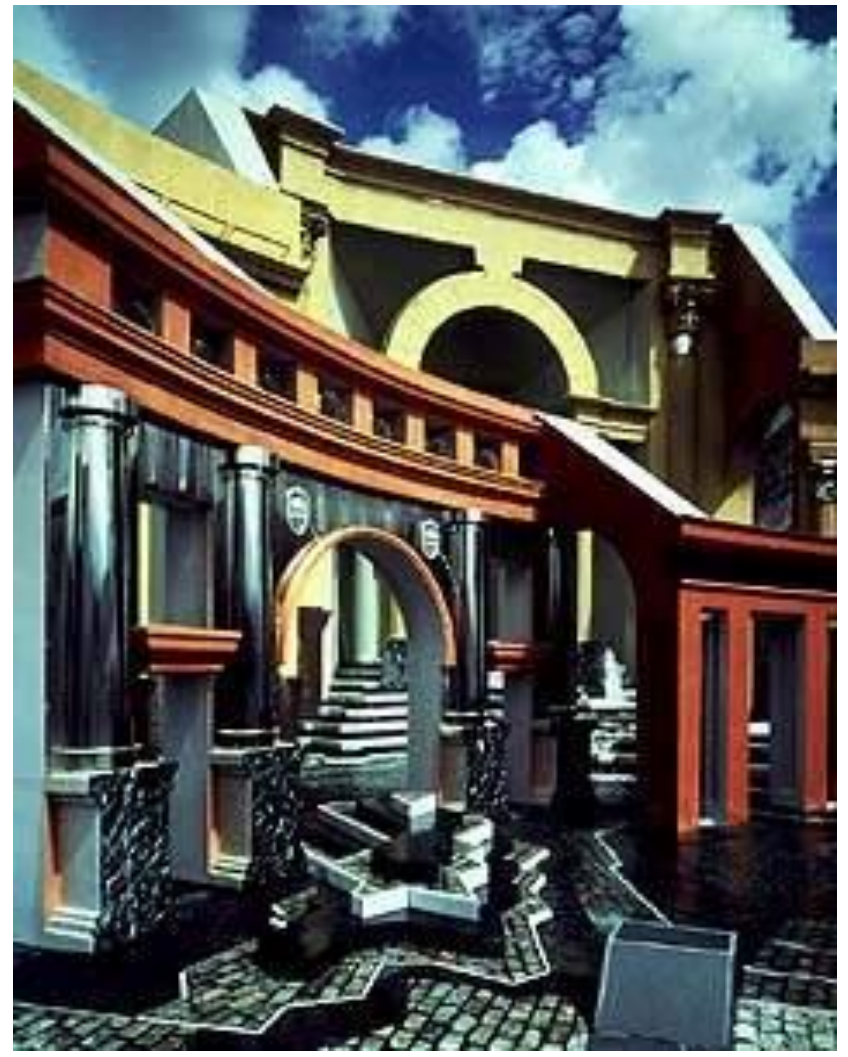

Figur 2. Piazzad ' Italia, New Orleans, Charles Moore, 1978

Post-modernism design opposes the uniformity and resemblance in product appearance which is characteristic of modernism. Modernism products tend to resemble one another in appearance. According to architect Tom Wolfe, "What's the matter if someone accuses you of imitating Mies, Walter Gropius or Le Corbusier? Isn't it like a Christian following the example of Jesus Christ?"[4] For this very reason, modernism architecture and internationalism architecture emerged on its basis after World War II faced an avalanche of criticism for the monotonic, unvarying geometrical cubic boxes. Post-modernism design, on the contrary, has opened up broad horizons for the diversified expressions of design with an inclusive attitude which shrugged off rules and standards and tolerated variations and contradictions. Taking postmodernism architecture as an example, the noisy excitement, jocosity and passion for shows and entertainments of Piazzad ' Italia by Charles Moore, the fantasy, liveliness embedded in serenity and elegance of Walt Disney World Swan by Michael Graves and the daintiness, variability and eclecticism among contradictions of Venturi House Chestnut Hill by Robert Venturi all reflect distinctive individuality.

The fact that modernism design centers itself upon functionalism with little ornamentation does not indicate the absence of pursuit in form. With machine as its metaphor, modernism design is based on the internal mechanical logic with a pure and stern "machinery aesthetic" style recognized with a trace of elitism. Venturi used to criticize modernism design as adapted to the taste of minority, stating that design should consider the taste and preference of the mass public. In his Learning from Las Vegas, Venturi positively acknowledged in Las Vegas that "the architecture that appears vulgar and in disorder demonstrates an enticing dynamism and effectiveness". This "dynamism in disorder" of postmodernism design reflects the diversity and inclusiveness of post-modernism; and the style of "cluttered revelry" features popularity and antielitism in its aesthetic taste.

\section{SYMBOLIC CONNOTATION OF POST- MODERNISM DESIGN}

Post-modernism design language features the beauty of inclusiveness, positioning itself against the prioritization of functionality while integrating multiple connotations. The concept of functionalism in modernism design interprets the beauty of design as principally a functional beauty. Post-modernism design, on the other hand, seeks to comprehend the functionality and connotation of product in a more flexible and diversified way, believing that design may either reflect and express practical functions or emphasize the reflection of form and aesthetics, or more extensive connotation such as psychological emotion or social culture, where the insignificance or even omission of practical function is permitted. The understanding of product function and connotation by post-modernism design reflects the non-functionality tendency of products in a consumer society, where products are endowed with meanings and therefore become material media of expressing meanings, and instrumental objects become symbolic, meaningful objects. Through processing in various ways, post-modernism design enables products to achieve richly diversified visual objectives and aesthetic effects which in turn play a more dominant role in the connotation and value of products, hence transforming products into symbols expressed in certain forms. This is an important channel for products to expand their connotation and value in the consumer society.

In the Kettle for Alessi designed by Michael Graves, a whistle in the shape of a red bird is featured on the kettle tap which gives off a whistling sound when water boils. The bird-shaped whistle became a highlight of design, as the image as well as the humor and curiosity expressed in it has added multiple connotations - concreteness, ornamentation and curiosity - to the practical function of the kettle. Italian designer Ettore Sottsass designed numerous objects with unclear functions and ambiguous connotations. His Carlton bookshelf, exaggerated in shape and ambiguous in function, is more like an abstract work of sculpture than expected functions of normal bookshelves. Its surface is covered with a 
brightly colored plastic film, thus strongly ornamental and producing strong visual effects, of which the sense of form and sculptural beauty is not closely relevant to the practical functions of product. Aware of his own design, Sottsass said, "For me, design is a way to study life, a way to study society, politics, sex, food and design itself. To boil it down, it is a way to build an image about life."[5] Sottsass is known for his design with a cartoonlized style and mixed historical elements of design, while stimulating free imagination[6]. The design by Sottsass proves that designed object may become a symbol for imagination, beauty of form and radical exploration.

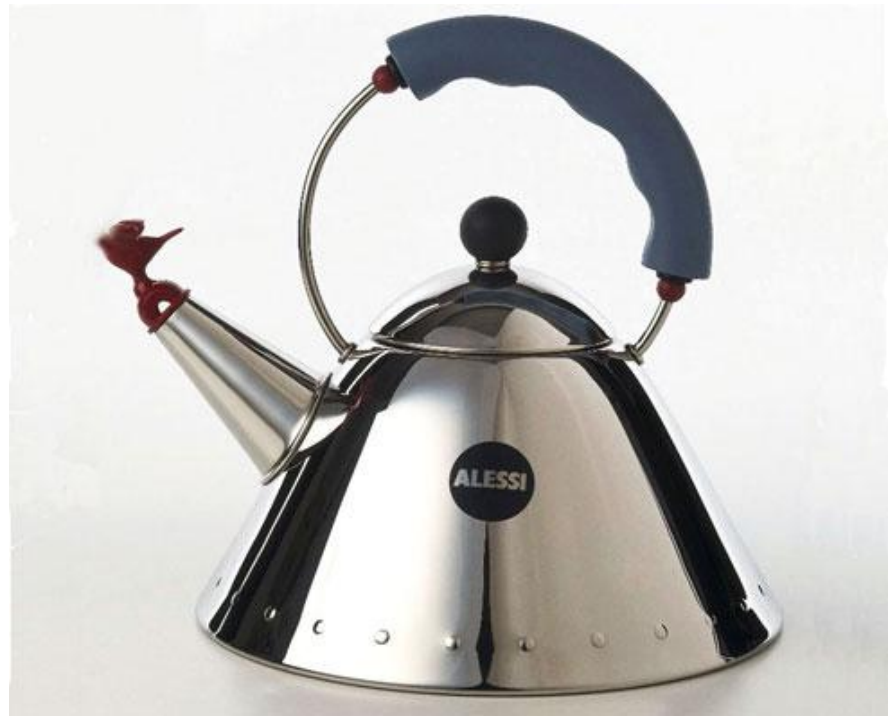

Figur 3. Kettle for Alessi, Michael Graves, 1985

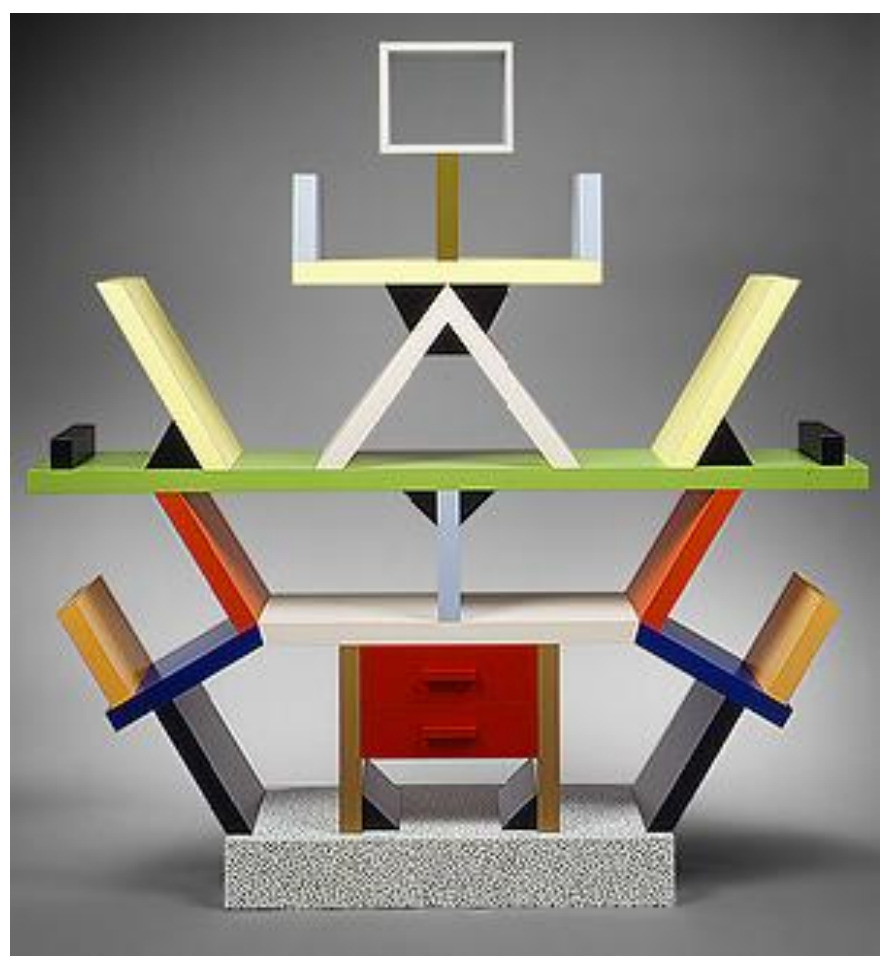

Figur 4. Carlton Bookshelf, Ettore Sottsass, 1981

\section{POST-MODERNISM AND \\ DECONSTRUCTION OF EXISTING ATT HIERARCHY}

With its integration of functionality, sense of form, artistic imagination and socio-cultural connotation, post-modernism design has shaped its unique aesthetic image in contemporary daily life. Postmodernism design products sheds light on the fact that daily objects around us are not only tools with practical functions and effects but also constitute a certain cultural symbol or quasi-artwork, which makes post-modernism design a typical pattern of aestheticization of contemporary daily life and postmodernism culture.

As a key landscape in aesthetic contemporary daily life scenarios, post-modernism design reflects the transformation and reshuffling of contemporary art and cultural patterns. In modern society, or even pre-modern society, the category of applied art was marginalized as "secondary art" in the art system. Although the emergence of modern design during the $19^{\text {th }}$ century, British scholar John Ruskin and designer William Morris advocated the demolition of boundary between applied art and pure art as well as their hierarchy, no fundamental changes were seen in the marginalization of design in art. Since the latter half of the $20^{\text {th }}$ century, design has been playing an increasingly role in contemporary production and life, hence moving rapidly from the margins of art and society towards the center. Jean Baudrillard pointed out that objects in the $20^{\text {th }}$ century have started to ascend the peak of art after playing an ornamental supporting role in art for a painfully long period[7] as he discussed on the contemporary position of objects. Despite the criticism for its conspiracy with product in materializing its market value and profit as well as the misrepresentation of quality by visual image of certain products, it would be impossible to turn a blind eye to the fact that artistic imagination and creativity which used to belong to pure art is beginning to migrate to daily objects, and that accompanied by the marginalization of conventional pure art in the contemporary world, design is glowing with increasingly splendor, shrugging off its past as a supporting role in obscurity. Contemporary design, including post-modernism design, is consistently providing contemporary daily life with enriched aesthetic objects and resources, and it is believed that no matter how the aestheticization of daily life is commented, the significance and value of post-modernism design will be further understood and appreciated in the interpretation of contemporariness as an important theoretical issue. 


\section{REFERENCES}

[1] Mike Featherstone, Consumer Culture and Postmodernism. tr. Liu Jingming, Nanjing: Yilin Press, 2000: 95-101.

[2] Jean Baudrillard, Consumer Society. tr. Liu Chengfu, Quan Zhigang, Nanjing: Nanjing University Press, 2001: 60, 121.

[3] Robert Venturi, Complexity and Contradiction in Architecture. tr. Zhou Buyi, Beijing: China Water \& Power Press, Intellectual Property Publishing House, 2006: 16 .
[4] Ling Jiyao et al., Art and Design Fifteen Class. Beijing: Peking University Press, 2006: 115.

[5] Li Yanzu (edit.) Selected Readings of Foreign Design Art Publications (II). Beijing: Tsinghua University Press, 2006:155

[6] Ann Ferebee, Jeff Byles. A History of Design from the Victorian Era to the Present, Liton Educational Publishing, Inc.2011, 178. 